\title{
Measurements of bridges' vibration characteristics using a mobile phone
}

\section{Medição de caracteristicas de vibração de pontes de concreto usando telefonia móvel}

\begin{abstract}
This research presents an alternative way to perform a bridge inspection, which considers the dynamics parameters from the structure. It shows an experimental phase with use of a mobile phone to extract the accelerations answers from two concrete bridges, from those records is feasible to obtain natural frequencies using the Fast Fourier Transform (FFT).Numerical models with uses finite element model (FEM) allow to determine the natural frequencies from the two concrete bridges and compare with the experimental phase of each one. The final results shows it's possible to use mobiles phones to extract vibration answers from concrete bridges and define the structural behavior of bridges from natural frequencies, this procedure could be used to evaluate bridges with lower costs.
\end{abstract}

Keywords: modal analysis, structural identification, inspection, monitoring.

\section{Resumo}

O presente artigo apresenta uma forma alternativa de inspeção para pontes que considera os parâmetros dinâmicos da estrutura. Trabalha na fase experimental com a extração de dados de aceleração com um aparelho de telefonia móvel e determinação de frequências naturais pelo uso da transformada rápida de Fourier (FFT) em dois viadutos em concreto. Ocorre ao mesmo tempo a modelagem em elementos finitos (MEF) de cada viaduto para a obtenção numérica das frequências. Posteriormente, é realizada a comparação entre as medições experimentais e os modelos numéricos. Os resultados finais mostram que é possível utilizar aparelhos de telefonia móvel para extrair dados de vibração e conhecer o comportamento estrutural de pontes através de frequências naturais, o que pode vir a ser usado para avaliação quantitativa e manutenção de pontes de maneira econômica.

Palavras-chave: análise modal, identificação estrutural, inspeção, monitoramento. 


\section{Introduction}

Bridges are typically installed in areas with rugged terrain in order to allow passage over depressions, rivers or seas, or in urban areas to facilitate the movement of vehicles. These structural systems require costly inspections that must be performed by people who are experienced in such ventures.

The structural elements of bridges must be visually inspected in order to identify cracks, excessive deformations, and reinforcements exposed to the naked eye. However, the elements are typically not readily accessible and although easy to perform, visual inspection is subjective because changes in the properties of the materials that compose the structural elements go unnoticed.

This drawback is overcome by monitoring the structures with instrumentation, which allows inspections through the use of dynamic modal parameters. The dynamic behavior of the structural system can be understood and the need for maintenance determined by defining these parameters.

Two concrete viaducts with differing spans were used as case studies in this work. These viaducts, referred to as Viaduct V1 and Viaduct V2, are located in Passo Fundo, Rio Grande do Sul and both are installed over a railroad. Numerical models and experiments were conducted. The objective is to compare the responses of the numerical models with those obtained from experiments. In addition, our goal is to confirm that the vibration response of the viaducts can be monitored using mobile devices. The damping was defined by applying the logarithmic decrement technique to the responses drawn in the time domain.

The process involves three steps: making the structure vibrate, extracting the acceleration response via accelerometers, and analyzing the obtained responses. The operational modal analysis was used to vibrate the structure by moving trucks across the viaducts. The data extraction was performed using an accelerometer fitted to a mobile device. In addition, the results were analyzed after applying a FFT to the extracted samples. The results of the numerical FEM of each viaduct were compared with those obtained from experiments. YOON[YOON] et al used a cell phone equipped with an accelerometer to check the natural frequency on $\mathbf{3 0}$ steel walkways in Seoul, South Korea. However, numerical models were not employed to complement the experimental measurements performed in that work. Current mobile phone models can perform such a task, since they are equipped with an internal accelerometer, which accurately reads the vibration on the $X, Y$, and $Z$ axes at acquisition rates of $50-200 \mathrm{~Hz}$. To achieve the objectives, we used a technique that allows the dynamic characteristics of a system to be defined through a mathematical model that best represents the behavior of the structure [HE]. Modal analysis can be performed experimentally or operationally, but in this study only the operational form of the method will be highlighted, owing to its relevance.

Operational modal Analysis was developed in the 1970s [THOMAS] and has attracted significant attention in the field of engineering owing to its use in marine platforms, buildings, towers, bridges, and other structures [ZHANG ]. This technique is based on the reading of the vibration response and provides information about the natural frequency, damping rate, and modal shapes.

Operationally, only structure response measurements are required; the excitation forces can neither be controlled nor quantified. This excitation may come from various sources, such as wind, vehicular traffic, and the operation of machines on the structure [MENDES]. According to [BAYRAKTAR ], compared to modal analysis performed experimentally, operational modal analysis is a rapid process that does not interfere with the operation of the structure; i.e., the excitation source is already working in the system, and therefore the measured responses represent the actual operating conditions. [MASJEDIAN] reported that the operational form represented the results of the entire system being analyzed; as such, this analysis is suitable for large and complex structures and can be used for the vibration control of structures and to identify damaged regions.

Modal analysis can be performed via two processes. The first uses the discretization technique (finite element method), which determines the rigidity and mass matrices of the structure. The second uses experimental data to define the natural frequencies, damping, and vibrational modes [LIMA].

A combination of theoretical and experimental modal analysis may be employed. For example, using experimental models (to scale) and numerical models, allows structures to be refined through a comparison of their responses [MEIRELLES]

This comparison indicates whether the numerical model is properly calibrated, and identifies damage-induced changes in the structural performance. The response changes with degradation of the structural components stemming from the gradual or sudden variation in the distribution and intensity of the load [ORCESI].

Changes in the physical properties (mass, rigidity, and damping) that adversely affect the modal parameters (natural frequencies and modal shapes) of the structure lead, in general, to structural damage. In other words, structural damage can result in changes to the dynamic characteristics of the structure [ZHAO]

FFT applied to the samples of the behavior in each case study transforms the data to the frequency-time domain. As a result, the frequency graphs show peaks that indicate the natural frequencies of the structure and verify the existence of vibrational modes [SAHIN]. The responses obtained from the numerical and FEM models as well as the experiments were compared. This comparison was performed in a continuous manner in order to validate the numerical model.

The frequency of a bridge is strongly dependent on the span length and the type of bridge construction. Frequency values of $2-4 \mathrm{~Hz}$ [[13] BACHMANN ] are typical but values $0-14 \mathrm{~Hz}$ have also been reported.

According to [MOHSENI ], the span length and the angle of inclination influence the natural frequency of bridges. In fact, the fundamental frequency decreases and increases with increasing length and angle of inclination, respectively. The angle of inclination also affects the vibrational mode of the structures. Bridges with an angle of inclination between $0^{\circ}$ and $45^{\circ}$ have predominantly modal bending shapes.

The damping rate of the structure is determined by the logarithm decrement, a technique that uses the recording of the excitation response during a harmonic fall. The decrement can be determined manually by analyzing the responses in the time domain [INMAN] [CANTIENI]. Moreover, this decrement is defined as the ratio of the number $n$ of consecutive, positive, integer periods and the value of amplitudes between the origin and end peaks considered.

\subsection{Justification}

According to [INMAN, D. J. Engineering Vibration. 3. ed. Upper 
Saddle River, New Jersey. Pearson Education, Inc., 2007. 669 p.

[16] CANTIENI, R. Dynamic Load Testing of Highway Bridges, IABSE PERIODICA, v. 3, 1984, p. 75-84. http://dx.doi.org/ 10.5169/ seals-38337

[17] ALSAIF ], bridges determine the carrying capacity of the road network traffic and are therefore key elements in the infrastructure system. Bridges are more costly to construct and maintain than roads, and hence a more precise analysis is required in order to avoid unnecessary expenses.

Once the need for an inspection is verified, current tools may be used to evaluate the structure of the bridge. The structural identification, also known as the monitoring system, is useful in this regard as it indicates, via instrumentation of the structure, the need for strengthening or replacement of existing bridges [WIBERGINMAN, D. J. Engineering Vibration. 3. ed. Upper Saddle River, New Jersey. Pearson Education, Inc., 2007. 669 p.

[16] CANTIENI, R. Dynamic Load Testing of Highway Bridges, IABSE PERIODICA, v. 3, 1984, p. 75-84. http://dx.doi.org/ 10.5169/ seals-38337

[17] ALSAIF ]. Furthermore, dynamic data can be obtained through the deployment of accelerometers on the special works of art to be evaluated.

The readings of vibration data are ideal for use as the basis for a continuous monitoring system, provided that they are easy to collect; these readings must also provide information about the overall performance by using only a few sensors [OWENINMAN, D. J. Engineering Vibration. 3. ed. Upper Saddle River, New Jersey. Pearson Education, Inc., 2007. $669 \mathrm{p}$.

[16] CANTIENI, R. Dynamic Load Testing of Highway Bridges, IABSE PERIODICA, v. 3, 1984, p. 75-84. http://dx.doi.org/ 10.5169/ seals-38337

\section{[17] ALSAIF ].}

According to [NEGRÃOINMAN, D. J. Engineering Vibration. 3. ed. Upper Saddle River, New Jersey. Pearson Education, Inc., 2007. 669 p.

[16] CANTIENI, R. Dynamic Load Testing of Highway Bridges, IABSE PERIODICA, v. 3, 1984, p. 75-84. http://dx.doi.org/ 10.5169/ seals-38337

[17] ALSAIF ], monitoring is performed on various structures, even those that do not require restoration. In the case of future bridges, the consequent increase in span length, combined with the desire to utilize narrower slabs, will lead to concerns about the dynamic behavior. New bridges should also be monitored before becoming operational (i.e., when they are in perfect condition) in order to obtain useful information for further evaluation.

According to[LOUIS], long service lives of these structures can be achieved if three parameters are fulfilled, namely, increased transport capacity, increased service life, and improved management, strengthening, and repair of the systems. Increased service life can be obtained only with the proper execution of inspection and maintenance.

\section{Materials and experimental program}

\subsection{Case studies}

The special works of art evaluated are both installed on railways located in areas belonging to the municipality of Passo Fundo, in the state of Rio Grande do Sul (RS). The structures are referred to as Viaduct $\mathrm{V} 1$ and Viaduct $\mathrm{V} 2$.

\subsubsection{Viaduct V1}

This $22.50 \mathrm{~m}$ (length) $\times 10.20 \mathrm{~m}$ (width) $\times 12.10 \mathrm{~m}$ (maximum central span) viaduct is located on highway BR 285 between Carazinho and Lagoa Vermelha in the municipality of Passo Fundo near the industrial district. In addition, the viaduct consists of two girders, five crossbeams, four piers, and four caps, and is located at geographic coordinates of $28^{\circ} 13^{\prime} 51,08^{\prime \prime} \mathrm{S}$ and $52^{\circ} 24^{\prime} 01,26^{\prime \prime} \mathrm{O}$.

\subsubsection{Viaduct v2}

This $36.00 \mathrm{~m}$ (length) $\times 10.60 \mathrm{~m}$ (width) $\times 24.00 \mathrm{~m}$ (maximum central span) viaduct is located on the Perimetral Leste, RS-135, in the city of Passo Fundo. Moreover, the viaduct consists of two girders, six crossbeams, four piers, and four caps and is located at geographic coordinates of $28^{\circ} 16^{\prime} 14,16^{\prime \prime} \mathrm{S}$ and $52^{\circ} 21^{\prime} 53,58^{\prime \prime} \mathrm{W}$.

\subsection{Materials and methods}

We used a Motorola RazrTM D1 mobile phone and a computer during the study. The mobile phone was equipped with a triaxial accelerometer, which was used to extract the acceleration responses of the viaducts. Furthermore, the natural frequencies were determined by using the computer to process the collected data.

We collected the vibration data by using the Vibration Monitoring software, a free application developed by Mobile Tools for the Android system. The application recorded the vibrations of the mobile device in real time and saved the registered vibrations in the memory. A vibrating table was used to calibrate the accelerometer that had a resolution of $0.0039 \mathrm{~m} / \mathrm{s}^{2}$, as determined by the application. In addition, sampling was performed at a rate of 100 samples/s, for individual sample times of $0.01 \mathrm{~s}$. Figure 1 shows the graphic

\section{Figure 1 - Graphic interface of software used to monitor the vibration}

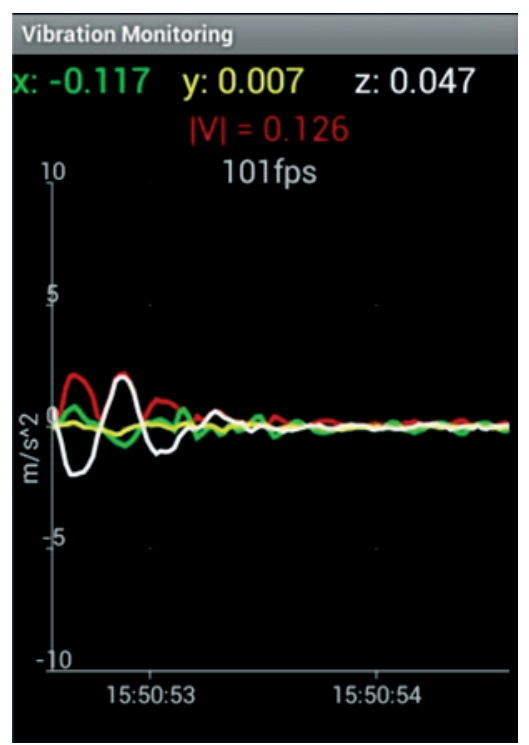




\section{Figure 2 - Points at which samples were extracted}

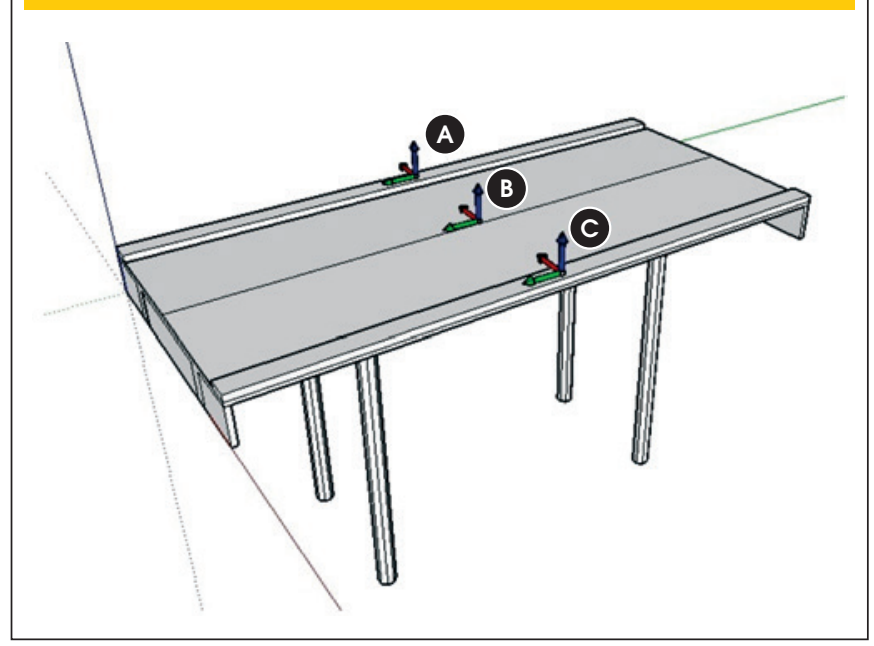

interface of the Vibration Monitoring application.

The SAP2000 software was used to model the viaduct. SAP2000 is an analysis programming platform for static finite elements that performs static or dynamic, linear or non-linear analysis, for the analysis and design of structures.

In addition, Scilab was used to process the signal being transformed into the frequency domain. Scilab is an open source software program that is used for programming numerical algorithms, which encompass various aspects of scientific computing.

\subsection{Survey of operating signals in the field}

The accelerometer was positioned in the middle of the largest span of each railroad viaduct in order to obtain the most amplified behavior of the structure. The vertical accelerations were extracted to the right and left of the cross-section and on the pavement markings that separate the lanes of each viaduct. Figure 2 shows the location of the points from which the samples were extracted.

Data extraction began when a truck stopped moving on the viaduct and finished before another truck, in any direction, reached the same viaduct. This ensured that the vibration of the viaduct stemmed only from its physical characteristics, i.e., influence from the interaction between the truck and the structure was prevented. Data storage, which was manually activated, was started and finished using the same criteria adhered to in the extraction stage. The motion of a truck on the viaduct constituted the ideal condition for saving data. Figure 3 shows the ideal state for the start of data storage. In (1), the truck approaches the viaduct, which is at rest. In (2), the viaduct is excited owing to the motion of the truck. In (3), when the truck leaves the viaduct, the structure responds to the stimulus of the vehicle and vibrates until returning to rest.

Controlled excitation was not used (e.g., a truck with known dimensions and weights, predetermined speed and weight) during the study. Instead, the excitation method of the structure was operational and, as such, the viaduct was subjected to daily traffic.

Figure 4 shows the result of the truck driving over the viaduct and indicates when data storage begins. In (a), before the truck reach- es the viaduct, there is no displacement acting on the structure. In (b), after the truck leaves, the viaduct vibrates owing to the presence of acceleration where the vertical displacements occur; data storage begins with this vibration.

The influence of vibration induced over the mobile phone on the data acquisition was prevented by attaching the mobile device to the selected points with double-sided tape.

\subsection{Data processing in the field and comparison with the numerical model}

The data was processed by applying an FFT to the samples. Moreover, the natural frequencies and modal shapes, which were based on the properties of the elements assigned to the structure, were obtained from the numerical model performed, via SAP2000, using finite elements.

The final modal parameter values obtained from the experimental and computational stages were compared.

\subsection{Analysis of the numerical models}

Various moduli of elasticity were obtained by calibrating and analyzing the models. The adjustments were finalized when both models, experimental and numerical, exhibited an appropriate response.

Figure 5 provides a brief illustration of the applied methodology. In (a), the bridge fitted for the measurement is subjected to excitation forces originating from vehicular traffic. The FFT is then applied to the response extracted in the time domain, thereby resulting in a transformation to the frequency domain. The resulting peak areas of the transformation represent the natural frequency of the viaduct being analyzed.

In (b), the bridge is physically modeled (using finite elements), and once the adjustments are made to the model, the modal parameters of frequency and modal shape are determined. The corresponding damping ratio is obtained experimentally.

\section{Experimental study}

\subsection{Viaduct V1}

A total of seven samples were extracted from points $A, B$, and C: A: on the public walkway - Samples 1, 2, 3, and 4;

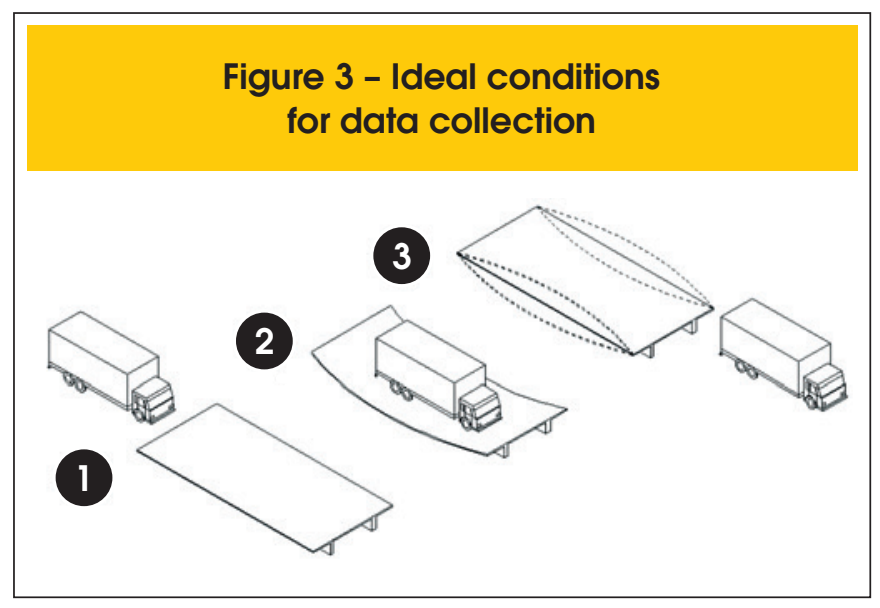


$B$ : in the center of the deck lanes on the markings - measurements were not performed at this location owing to the possibility of the traffic destroying the mobile device;

C: on the public walkway - Samples 5, 6, and 7 .

\subsubsection{Signals in the time domain}

The responses can be classified as free vibration. Figure 6 presents one of the sources of vibration used and Figure 7 presents one of the samples taken from Viaduct V1.

\subsubsection{Damping of viaduct V1}

Viaduct $\mathrm{V} 1$ had an average damping rate of $\xi=0.0175$ (i.e., the damping rate was $1.75 \%$ ). Table 1 shows the damping rates obtained by applying the technique of random decrement to all of the samples. However, sample 7 did not exhibit the necessary logarithmic decrement. As such, the damping associated with the sample could not be determined.

\subsubsection{Signals in the frequency domain of viaduct V1}

In the frequency domain, samples 1, 2, 3, 4, 5, 6, and 7 exhibited frequency peaks ranging from $7-14 \mathrm{~Hz}$.

Samples 1, 2, 3, and 4 (taken at point A) exhibited frequency peaks of $\mathrm{f} 1=12.30 \mathrm{~Hz}, \mathrm{f} 2=13.08 \mathrm{~Hz}, \mathrm{f} 3=11.72 \mathrm{~Hz}$, and $\mathrm{f} 4=12.60 \mathrm{~Hz}$. In addition, samples 5,6 , and 7 (taken at point $\mathrm{C}$ ) had frequencies of $f 5=14.45 \mathrm{~Hz}, \mathrm{f} 6=13.08 \mathrm{~Hz}$, and $\mathrm{f} 7=7.81 \mathrm{~Hz}$. Figure 8 shows the frequencies corresponding to sample 1 , which had a natural frequency of $12.30 \mathrm{~Hz}$.

\subsection{Viaduct V2}

Data was extracted from nine samples taken at points $A, B$, and $C$ of Viaduct V2; i.e.,

A: on the public walkway - Samples 1, 2, 3;

$\mathrm{B}$ : in the center of the deck lanes on the markings - Samples 7, 8, 9;

C: on the public walkway - Samples 4, 5, 6 .

\subsubsection{Signals in the time domain}

Figure 9 shows a sample taken from Viaduct V2.

\subsubsection{Damping of viaduct V2}

An average damping rate of $\xi=0.012$ (i.e., $1.2 \%$ ) was obtained for Viaduct V2. Table 2 shows the damping values for each sample taken at Viaduct V2.Table Samples 6, 7, and 8 did not exhibit the necessary logarithmic decrement. As such, damping could not be determined in the case of these samples.

\subsubsection{Signals in the frequency domain of viaduct $\mathrm{V} 2$}

The samples taken show frequency values ranging from

\section{Figure 4 - Result of truck movement on the viaduct}

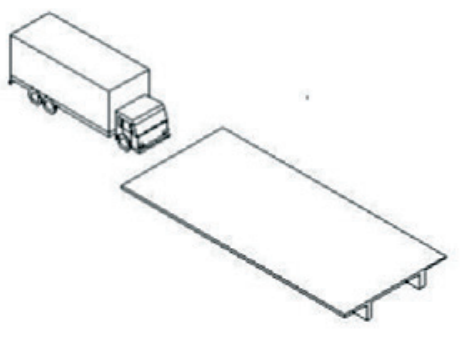

A

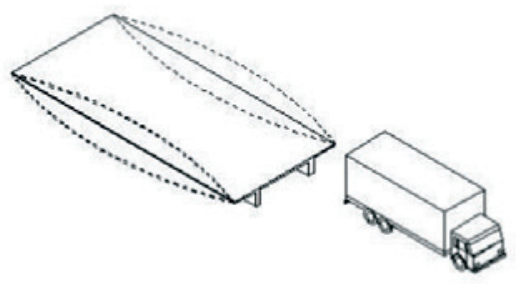

B
Before vehicle passes

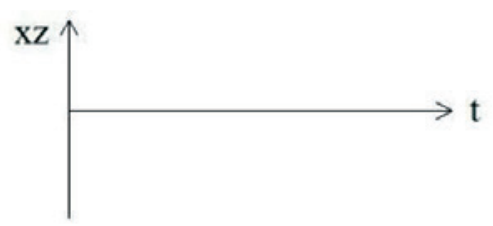

After vehicle passes

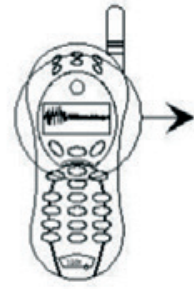

$\mathbf{x z} \uparrow$

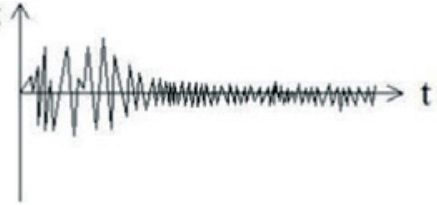


5.96-7.42 Hz. Samples 4, 5, 7, and 9 had, in addition to the structure-related frequencies, peaks at $\sim 15$ and $20 \mathrm{~Hz}$. These are probably associated with the source of vibration of the structure and the interaction between the trucks and the viaduct. However, traffic interference resulted in noise in the frequencies of samples 6 and 8 , which made it impossible to identify the structure-related frequency. Figure 10 shows sample 1 in the frequency domain. As the figure shows, sample 1 has a natural frequency of $6.44 \mathrm{~Hz}$.

\section{Numerical modeling}

\subsection{Viaduct V1}

The numerical model of Viaduct $\mathrm{V} 1$ was divided into a grid of $\sim 50 \times 50$ $\mathrm{cm}, 50 \times 18 \mathrm{~cm}$, and $50 \times 18 \mathrm{~cm}$ on the board, girders, and crossbeams, respectively. The corresponding analysis was performed via shells.

\subsubsection{Boundary conditions}

The four existing piers were considered embedded and the translational movement in $\mathrm{Z}$ was restricted at the longitudinal ends where the girders and crossbeams were located. In addition, translational movement along the $\mathrm{X}$ and $\mathrm{Y}$ axes was restricted at the ends of the crossbeams.

\subsubsection{Material properties}

The material properties used in the numerical model are those of concrete that has a specific weight, strength, Poisson ratio, and modulus of elasticity of $25 \mathrm{KN} / \mathrm{m}^{3}, 20 \mathrm{MPa}, 0.2$, and $25 \mathrm{GPa}$, respectively, [NBR 6188/2014].

\section{Figure 5 - Summary of methodology}

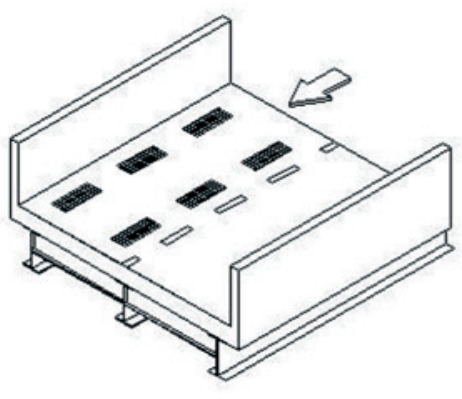

A そ)

Time response

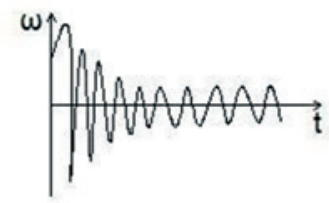

$\checkmark$ FFT

Frequency response

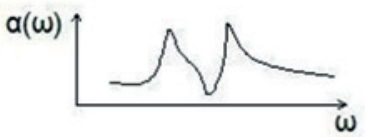

ร

$\omega=$ Angular Frequency
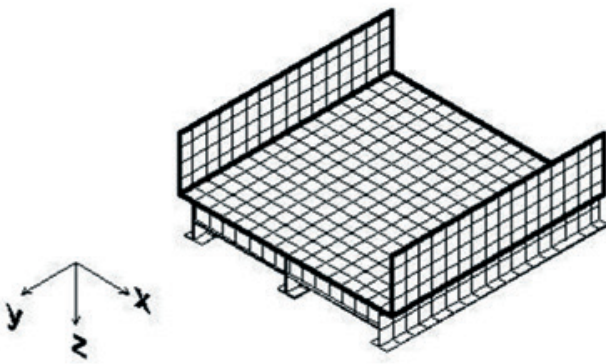

B

F.E.M<smiles>C1[Te]C2CC12</smiles>

Modal Parameters

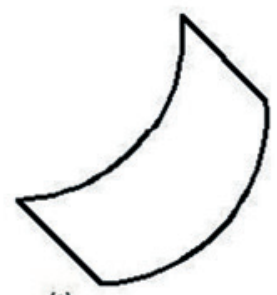

$\{\varnothing\}$ 

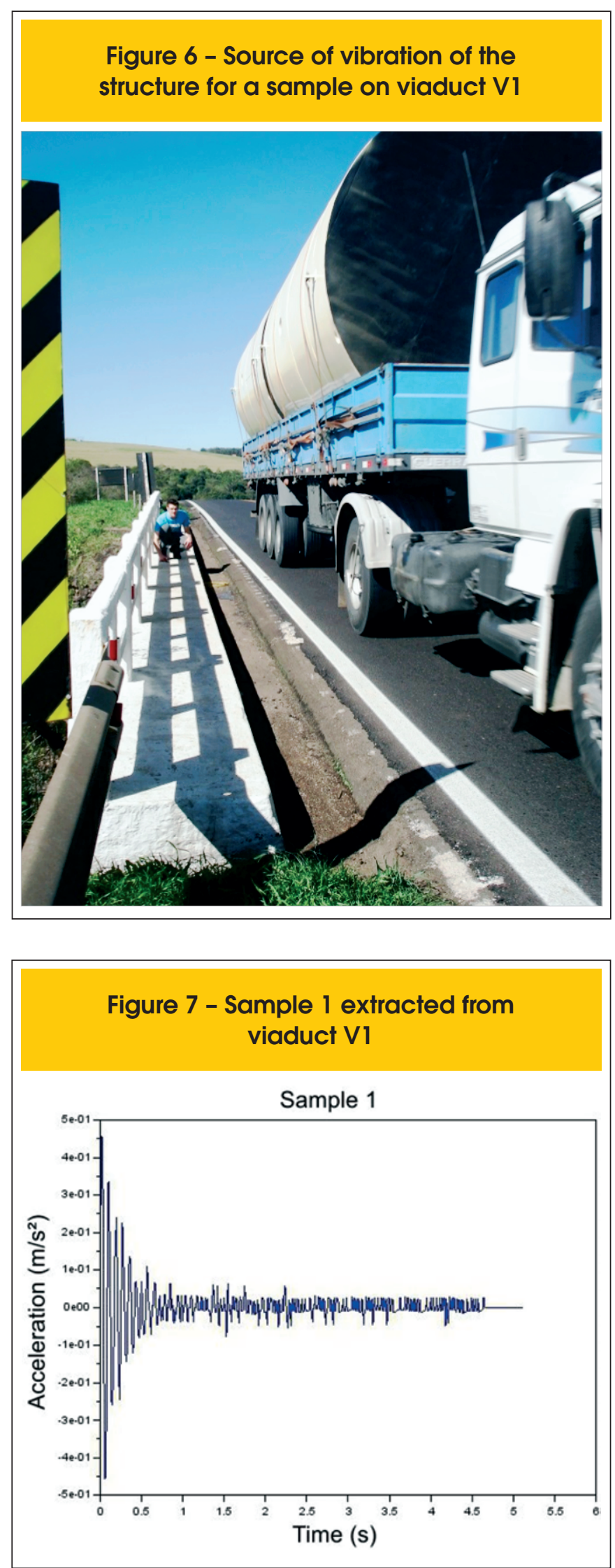

\section{Figure 8 - Frequency corresponding to sample 1 in viaduct $\mathrm{V} 1$}

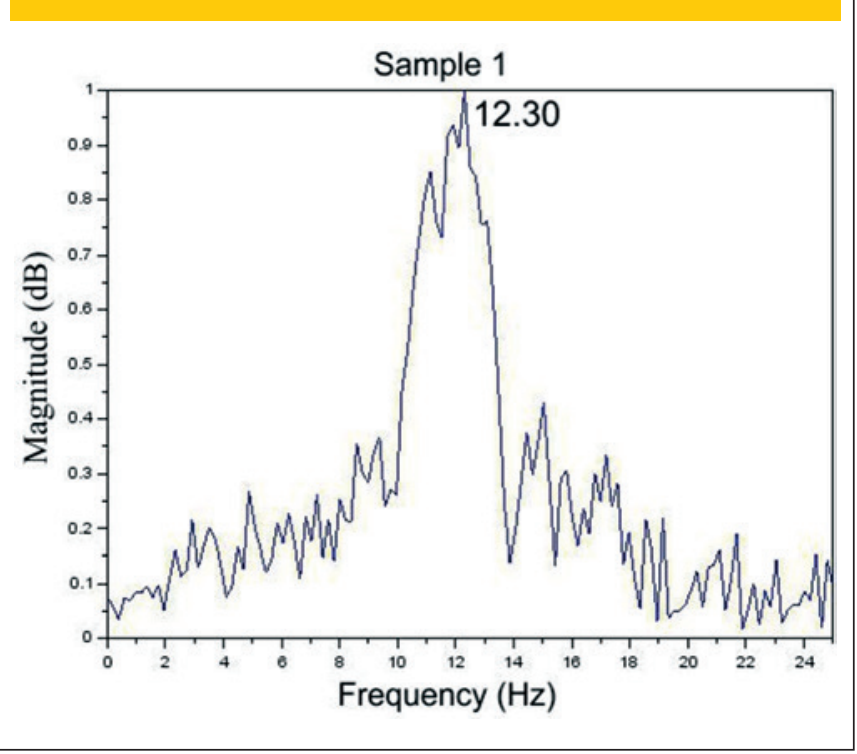

\subsubsection{Existing masses}

Masses corresponding to the parapets were added to the numerical model.

\subsubsection{Natural frequencies and vibrational modes}

Natural frequencies and vibration modes of $\mathrm{f} 1=11.64 \mathrm{~Hz}, \mathrm{f} 2=$ $12.03 \mathrm{~Hz}$, and $\mathrm{f} 3=13.78 \mathrm{~Hz}$ corresponding to the torsion, bending, and (again) torsion modes were obtained after modal analysis. Moreover, using f2 $=12.03 \mathrm{~Hz}$ and the bending modal shape yields the closest correspondence to the experimental results. Figure 11 shows the modal shapes resulting from the analysis performed using SAP2000 and Table 3 lists the vibrational modes and natural frequencies associated with the structure.

\begin{tabular}{|cc|}
\hline Table 1 - Damping ratio obtained for viaduct V1 \\
\hline Sample & Damping $(\xi)$ \\
\hline 1 & 0.020 \\
\hline 2 & 0.013 \\
\hline 3 & 0.027 \\
4 & 0.011 \\
5 & 0.015 \\
\hline 6 & 0.019 \\
\hline 7 & - \\
\hline Average rate of damping & 0.0175 \\
\hline Standard deviation $(\sigma)$ & 0.0058 \\
\hline Coefficient of variation & $33 \%$ \\
\hline
\end{tabular}




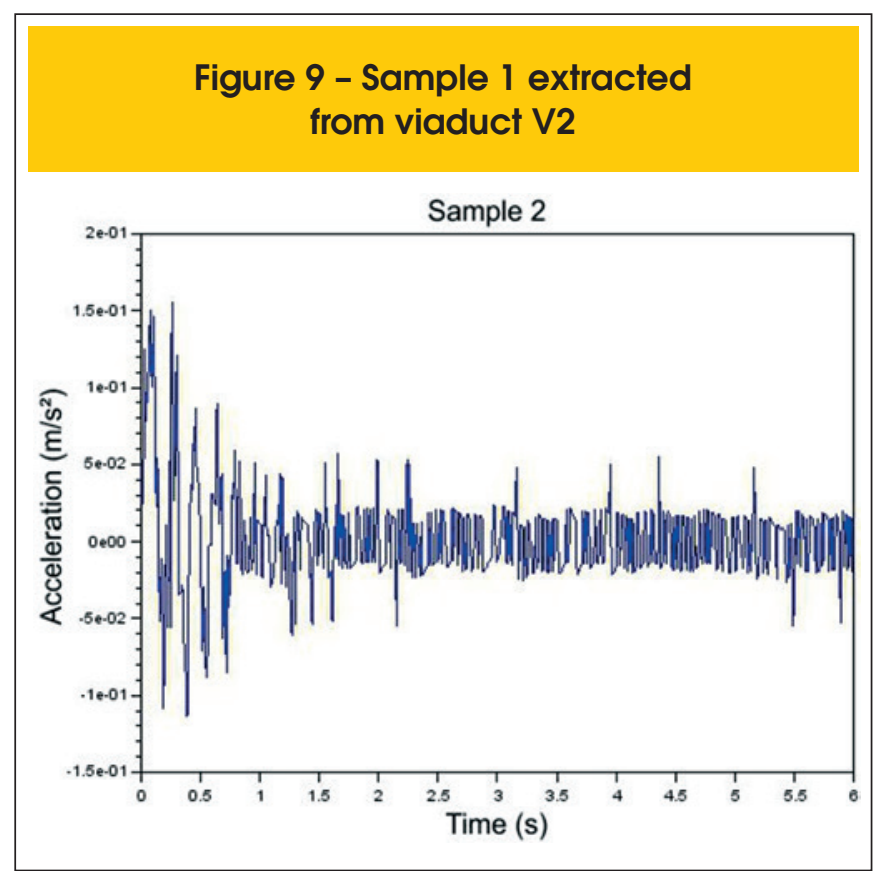

\subsection{Viaduct V2}

The numerical model of Viaduct $\mathrm{V} 2$ had dimensions of $\sim 50 \times 50 \mathrm{~cm}$, $50 \times 20 \mathrm{~cm}$, and $50 \times 20 \mathrm{~cm}$ on the board, girders, and crossbeams, respectively. The corresponding analysis was performed via shells.

\subsubsection{Boundary conditions}

The same boundary conditions were used as those adopted for Viaduct V1.

\section{Table 2 - Damping ratio obtained for viaduct V2}

\begin{tabular}{|cc|}
\hline Sample & Damping $(\xi)$ \\
\hline 1 & 0.012 \\
\hline 2 & 0.007 \\
\hline 3 & 0.014 \\
4 & 0.013 \\
\hline 6 & 0.015 \\
7 & - \\
\hline 8 & - \\
\hline 9 & 0.0175 \\
- & - \\
\hline 0.010 & $33 \%$ \\
\hline Average rate of damping & - \\
\hline Standard deviation $(\sigma)$ & 0.012 \\
\hline Coefficient of variation & 0.003 \\
\hline
\end{tabular}

\section{Figure 10 - Frequency corresponding to sample 1 in viaduct $\mathrm{V} 2$}

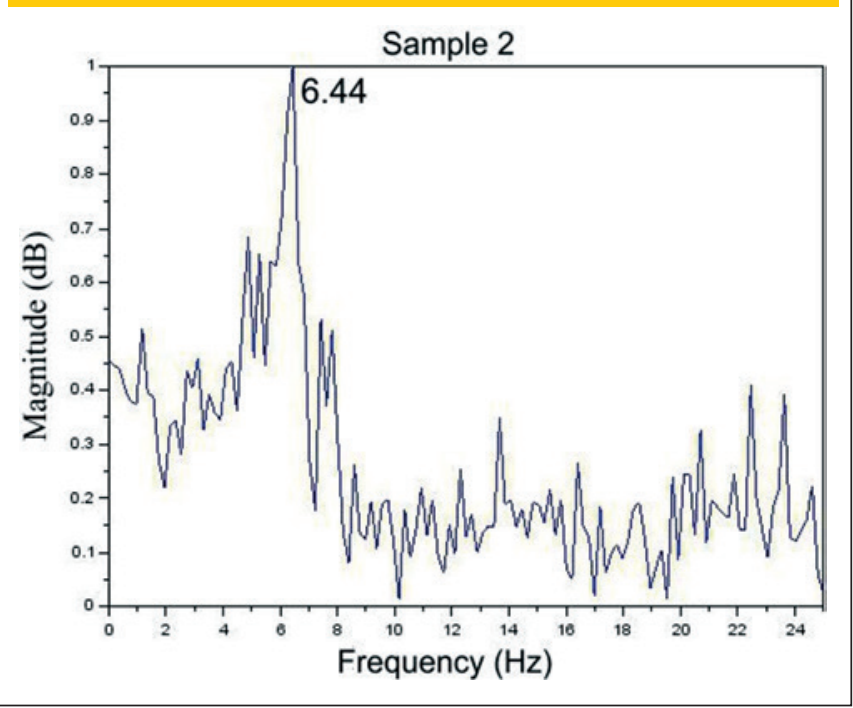

\subsubsection{Material properties}

The material properties used in the numerical model of this viaduct corresponded to those of concrete that had a strength, specific weight, and Poisson coefficient of $18 \mathrm{MPa}, 25 \mathrm{KN} / \mathrm{m}^{3}$, and 0.2 [ASSOCIAÇÃO ], respectively.

An elastic modulus of $20 \mathrm{GPa}$ was adopted, as determined by using equation 1 :

$$
E_{c i}=\alpha_{E} .5600 \sqrt{f c k}
$$

Where the parameter was based on the nature of the aggregate that influences the modulus of elasticity $\left(\alpha_{E}\right)$ :

$$
\alpha_{i}=0.8+0.2 \cdot \frac{f_{c k}}{80} \leq 1.0
$$

In accordance with the NBR 6118/2014 standard, equation 1 was used to determine the modulus of elasticity of concrete that has a resistance of 20-50 $\mathrm{MPa}$.

\subsubsection{Existing masses}

The masses of the parapets were also included in the numerical model.

\subsubsection{Natural frequencies and vibration modes}

The frequencies and vibration modes obtained were: $\mathrm{f} 1=6.93 \mathrm{~Hz}$ in the torsion mode; $\mathrm{f} 2=7.57 \mathrm{~Hz}$ in the bending mode; $\mathrm{f} 3=10.13 \mathrm{~Hz}$ in the transverse mode. 


\section{Figure 11 - Modal shapes used in the numerical modeling of viaduct V1}

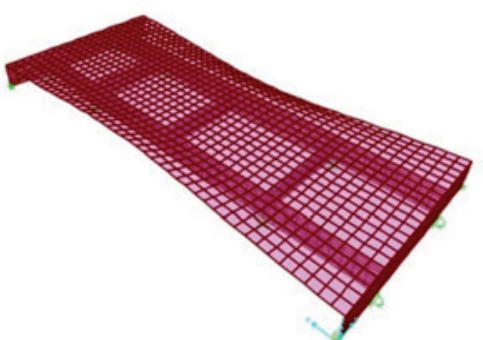

1

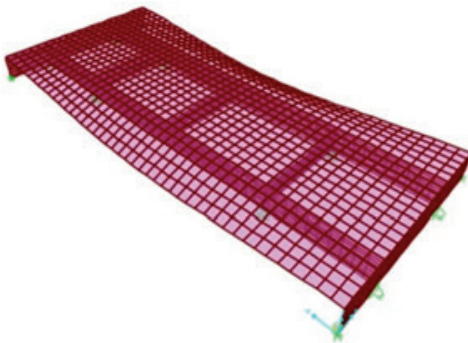

2

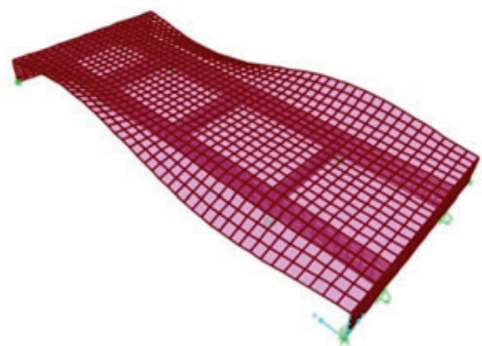

3
Table 3 - Frequencies and modal shapes of viaduct $\mathrm{V} 1$

Vibrational modes Frequency $\mathrm{f}(\mathrm{Hz}) \quad$ Modal shape

$\begin{array}{lll}1 & 11.64 & \text { Torsion } \\ 2 & 12.03 & \text { Flexion } \\ 3 & 13.78 & \text { Torsion }\end{array}$

Furthermore, a frequency of $\mathrm{f} 2=7.57 \mathrm{~Hz}$ in the bending mode yielded the closest correspondence to the experimental results. Figure 12 shows the modal shapes resulting from the analysis performed using SAP2000 and Table 4 lists the vibrational modes and natural frequencies associated with the structure.

\subsection{Evaluation of the outcome}

As previously stated, a frequency of $12.03 \mathrm{~Hz}$ in the bending mode of

\begin{tabular}{|c|c|c|}
\hline \multicolumn{3}{|c|}{$\begin{array}{c}\text { Table } 4 \text { - Frequencies and modal shapes } \\
\text { of viaduct V2 }\end{array}$} \\
\hline Vibrational modes & Frequency $\mathrm{f}(\mathrm{Hz})$ & Modal shape \\
\hline 1 & 6.93 & Torsion \\
\hline 2 & 7.57 & Flexion \\
\hline 3 & 10.13 & Transverse \\
\hline
\end{tabular}

Viaduct $\mathrm{V} 1$ resulted in the closest correspondence to the experimental results, especially in the case of samples 1 and 4 . Experimentally determined frequencies ranging from $7.81-14.45 \mathrm{~Hz}$ were obtained. Similarly, in the case of Viaduct V2, a frequency of $7.57 \mathrm{~Hz}$ in the bending mode yielded the closest correspondence to the experimental results (i.e., a frequency of $7.42 \mathrm{~Hz}$ for sample 4); the experimentally determined frequencies range from $5.96-7.42 \mathrm{~Hz}$. Table 5 compares the numerical and experimental frequencies of Viaducts V1 and V2.

\section{Figure 12 - Modal shapes used in the numerical modeling of viaduct V2}

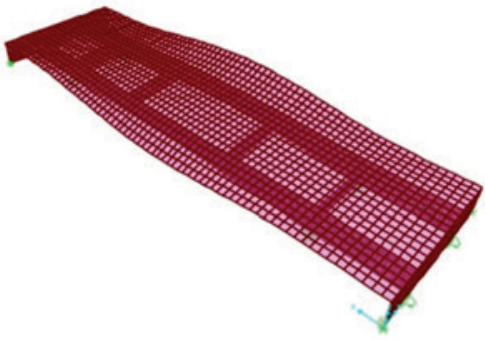

1

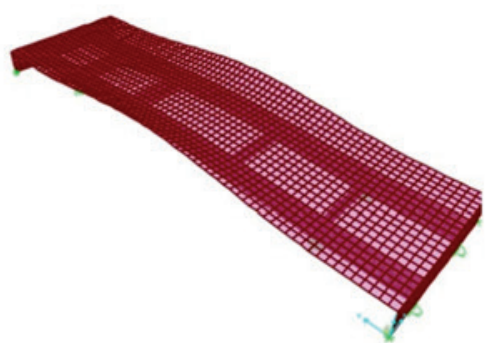

2

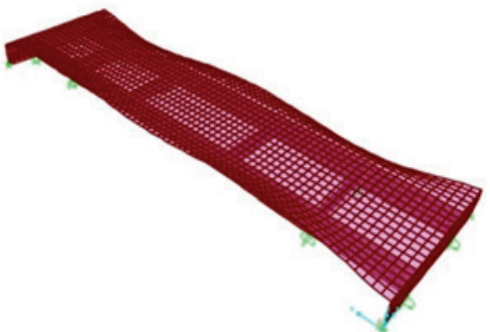

3 


\section{Table 5 - Numerical and experimental frequencies obtained}

\begin{tabular}{|c|c|c|c|c|}
\hline & \multicolumn{2}{|c|}{ Numerical model } & \multicolumn{2}{|c|}{ Experimental results } \\
\hline & Vibration modes & Frequency $(\mathrm{Hz})$ & Sample & Frequency $(\mathrm{Hz})$ \\
\hline \multirow{7}{*}{ Viaduct V1 } & 1 - Torsion & 11.64 & 1 & 12.31 \\
\hline & 2 - Flexion & 12.03 & 2 & 13.08 \\
\hline & 3 - Torsion & 13.78 & 3 & 11.72 \\
\hline & - & - & 4 & 12.60 \\
\hline & - & - & 5 & 14.45 \\
\hline & - & - & 6 & 13.08 \\
\hline & - & - & 7 & 7.81 \\
\hline \multirow{9}{*}{ Viaduct V2 } & 1 - Torsion & 6.93 & 1 & 6.05 \\
\hline & 2 - Flexion & 7.57 & 2 & 6.44 \\
\hline & 3 - Transverse & 10.13 & 3 & 6.25 \\
\hline & - & - & 4 & 7.42 \\
\hline & - & - & 5 & 6.44 \\
\hline & - & - & 6 & Noise \\
\hline & - & - & 7 & 5.96 \\
\hline & - & - & 8 & Noise \\
\hline & - & - & 9 & 6.49 \\
\hline
\end{tabular}

The frequencies obtained in Viaducts V1 and V2 fall within the frequency band of 0-14 Hz, proposed for bridges [13].

In addition, [[13] BACHMANN ] indicates that for bridges, the damping parameter must be $\leq 2 \%$.

With damping values of $1.75 \%$ and $1.2 \%$, respectively, Viaducts V1 and $\mathrm{V} 2$ both satisfied this criterion.

\section{Conclusions}

The results obtained and the methodology developed, confirmed that natural excitation, e.g., truck traffic, was effective in vibrating the structure; extracting the necessary acceleration data was therefore possible.

The triaxial accelerometer fitted to the mobile device acquired vibration data from the viaducts and therefore constituted an alternative to the traditional vibration test performed with accelerometers created for this purpose.

Data was extracted rapidly and simply, but required care to prevent the extracted samples from being affected by vehicular traffic. Even then, a small number of samples were rendered unusable owing to the interaction between the vehicles and the structure. The duration of the samples, although variant, revealed the natural frequency of the structures without influencing the results.

The experimentally obtained frequencies fell within the range of values $(0-14 \mathrm{~Hz})$ proposed [[13] BACHMANN ] for bridges.

Responses from the numerical modeling of both viaducts exhibited close correspondence to those observed experimentally. Therefore, the models are calibrated and will soon be ready for possible simulations of the structural performance of each viaduct. The damping in each viaduct was $<2 \%$, which is in accordance with the generally accepted criterion [[13] BACHMANN ] for bridges. Therefore, the process of using the natural excitation for extraction of vibration data with mobile phones equipped with accelerometers is appropriate, reliable, and very economical. The final numerical and experimental results obtained indicated that it is possible to determine the natural frequency and damping, and to monitor special artworks in an alternative manner, without the need for intervening traffic; this can be achieved readily, reliably, and at a low cost by using mobile devices.

\section{Bibliographic references}

[1] YOON et al. Vibration Measurements of Steel Foot-bridges using Mobile-phone. Applied Mechanics and Materials, v. 470, 2014, p. 471-493. http://dx.doi.org/10.4028/www.scientific.net/AMM.470.777

[2] HE, J. FU, Z. Modal Analysis. 1. ed. Oxford: University of Oxford, 1. ed. 2001. 291 p. http://papai.ucoz.hu/konyvek/ He-Fu_Modal-Analysis.pdf

[3] THOMAS et al. Identification of modal parameters by operational modal analysis for the assessment of bridge rehabilitation. In: 2nd, PROCEEDINGS OF THE INTERNATIONAL OPERATIONAL MODAL ANALYSIS CONFERENCE, 2007. http://www.academia.edu/829984/IDENTIFICATION_OF_ MODAL_PARAMETERS_BY_OPERATIONAL_MODAL_ ANALYSIS_FOR_THE_ASSESSMENT_OF_BRIDGE_REHABILITATION

[4] ZHANG et al. An overview of operational modal analysis: major development and issues. In: 1st, INTERNATIONAL OPERATIONAL MODAL ANALYSIS, 2005. http://vbn. 
aau.dk/en/publications/an-overview-of-operational-modalanalysis(eacacb00-346d-11db-a718-000ea68e967b).html

[5] MENDES, P; OLIVEIRA, S. Análise dinâmica de estruturas: utilização integrada de modelos de identificação modal e modelos de elementos finitos. LNEC: Laboratório Nacional de Engenharia Civil, Lisboa, 2008.

[6] BAYRAKTAR et al. Ambient Vibration Tests of a Steel Footbridge. Journal of Nondestructive Evaluation, v. 29, 2010; $p$. 14-24. http://dx.doi.org/ 10.1007/s10921-009-0061-9

[7] MASJEDIAN, H, M; KESHMIRI, M. A review on operational modal analysis researches: classification of methods and applications. In: 3, IOMAC'09, INTERNATIONAL OPERATIONAL MODAL ANALYSIS CONFERENCE, 2009. http:// www.iomac.dk/sync/uploads/d1a86b9c8297ae2d1736272a1c2a4b8e.pdf

[8] LIMA, A, N, M. Testes modais utilizando martelo instrumentado em estruturas de baixas frequências naturais, João Pessoa, 2006, Dissertação (Mestrado) - Universidade Federal da Paraíba, 58 p. http://bdtd.biblioteca.ufpb.br/tde_busca/arquivo.php?codArquivo $=319$

[9] MEIRELLES, B, F, J. Análise dinâmica de estruturas por modelos de elementos finitos identificados experimentalmente, Guimarães, 2007, Tese (Doutorado) - Universidade de Minho, 344 p. https://repositorium.sdum.uminho.pt/bitstream/1822/8059/1/PHD-Meireles\%20Revision\%208e.pdf

[10] ORCESI, D, A; FRANGOPOL, M, D. Bridge Performance Monitoring Based on Traffic Data. Journal of Engineering Mechanics, v. 139, 2013, p. 1508-1520. http://dx.doi. org/10.1061/(ASCE)EM.1943-7889.0000582

[11] ZHAO, J; ZHANG, J. Structural Damage Identification Based on the Modal Data Change. International Journal of Engineering and Manufacturing, v. 4, 2012, p. 59-66. http:// dx.doi.org/10.5815/ijem.2012.04.08

[12] SAHIN, A; BAYRAKTAR, A. Forced-Vibration Testing and Experimental Modal Analysis of a Steel Footbridge for Structural Identification. Journal of Testing and Evaluation, v. 42, 2014, p. 695-712. http://dx.doi.org/ 10.1520/JTE20130166

[13] BACHMANN et al. Vibration Problems in Structures: Practical Guidelines. Birkhäuser Verlag, 1995. 248 p.

[14] MOHSENI et al. A Simplified Method to Estimate the Fundamental Frequency of Skew Continuous Multicell BoxGirder Bridges. Latin American Journal of Solids and Structures, v. 11, 2014, p. 649-658. http://dx.doi.org/ http://dx.doi. org/10.1590/S1679-78252014000400006

[15] INMAN, D. J. Engineering Vibration. 3. ed. Upper Saddle River, New Jersey. Pearson Education, Inc., 2007. 669 p.

[16] CANTIENI, R. Dynamic Load Testing of Highway Bridges, IABSE PERIODICA, v. 3, 1984, p. 75-84. http://dx.doi.org/ $10.5169 /$ seals-38337

[17] ALSAIF et al. Field study for the evaluation of steel bridges in Riyadh City. In: SAUDI ENGINEERING CONFERENCE (SEC7), 7., 2007, Riyadh, Arábia Saudita. http://faculty.ksu. edu.sa/mmadany/Publications/list $\% 20$ Publication/Field\%20 Study\%20for\%20the\%20Evaluation.pdf

[18] WIBERG, J. Bridge monitoring to allow for reliable dynamic FE modelling: a case study of the new Årsta Railway Bridge. Stockholm, Sweden: KTH, 2006. 151 p. http://www.divaportal.org/smash/get/diva2:9925/FULLTEXT01.pdf
[19] OWEN, S, J; PEARSON, R, S; The use of dynamic data for the structural health monitoring of bridges. In: INTERNATIONAL SYMPOSIUM ON ENGINEERING SURVEYS FOR CONSTRUCTION WORKS AND STRUCUTRAL ENGINEERING, 1., 2004, United Kingdom. https://www.fig.net/ nottingham/proc/ts_04_1_owen_pearson.pdf

[20] NEGRÃO, O, H, J; SIMÕES, C, M, L. Dimensionamento e optimização da geometria de pontes em tirantes metálicas. In: III, ENCONTRO NACIONAL DE MECÂNICA COMPUTACIONAL, 1992. http://www.researchgate.net/publication/236133594_Dimensionamento_e_Optimizao_da_ Geometria_em_Pontes_de_Tirantes_Metlicas

[21] LOUIS, A. R. Sustainable Bridges: Green Links to the Future, Ohio, 2010, Dissertação (Mestrado) - The Ohio State University, 91 p. https://etd.ohiolink.edu/ap:0:0:APPLICATION PROCESS = DOWNLOAD_ETD_SUB_DOC_ ACCNUM:::F1501_ID:osu1274455847, attachment

[22] ASSOCIAÇÃO BRAASILEIRA DE NORMAS TÉCNICAS. Projeto de estruturas de concreto - NBR 6118, Rio de Janeiro, 2014. 